\title{
Condom Use and HIV Testing on Female Sex Workers
}

\author{
Muhammad Azinar ${ }^{1}$, Alfiana Ainun Nisa ${ }^{2}$, Arulita Ika Fibriana ${ }^{3}$ \\ $\left\{\right.$ azinar.ikm@mail.unnes.ac.id ${ }^{1}$, alfiana_ainun@mail.unnes.ac.id ${ }^{2}$, arulita.ika.f@mail.unnes.ac.id $\left.{ }^{3}\right\}$
}

Universitas Negeri Semarang, Semarang, Indonesia ${ }^{1,2,3}$

\begin{abstract}
This research is an descriptive-correlative study with cross sectional design using a quantitative approach to predict the practice of Condom-Use and HIV-Test among female sex workers in the lokalisasi area of Batang district. The population were all FSW in the localization area of Batang Regency, which are the population at highest risk of contracting and transmitting HIV/AIDS. The sample selection technique was simple random sampling. Data collection is done by filling out a questionnaire. Data analysis was carried out descriptively and correlatively with the Chi Square test. The results showed that the practice of using condoms in sexual activities carried out by FSW and their customers was still low, namely only $30.1 \%$. Factors that significantly influence the practice of using condoms consistently in every sexual activity performed by FSW and their clients are perceptions of vulnerability to HIV transmission, perceptions of HIV/AIDS severity, perceptions of condom benefits, perceived barriers to condom access, customer support and self-efficacy. Factors that significantly influence the practice of HIV testing among FSW are perceptions of vulnerability to HIV transmission, perceptions of HIV/AIDS severity, perceptions of the benefits of HIV testing, perceptions of barriers to HIV testing, knowledge of HIV/AIDS, pimp support and selfefficacy.
\end{abstract}

Keywords: PMT, condom-use, HIV-test.

\section{Introduction}

HIV/AIDS is still a global and national health problem with the number of new cases increasing every year. Central Java is the province with the fifth largest HIV / AIDS case. Every day an average of 10 new cases were found [1].

One of the HIV/AIDS red zone areas is Batang district. This region has a high risk of HIV/AIDS transmission because of the large number of localizations that are scattered along the coast of Java Island. The Batang Regency AIDS Commission (KPA) said HIV/AIDS cases in Batang have always been on the increase. From 2007 to June 2018 there have been 1,039 HIV/AIDS cases, 165 of which have died. In the past year, in Batang District, 75 new cases of HIV/AIDS have been found and 10 people have died [2].

HIV/AIDS in Batang district in the past year was dominated by women (63\%) and most of them came from female sex workers (FSW). FSW is the group that has the greatest risk factor due to sexual behavior that has multiple partners [2]. This fact shows that HIV / AIDS is increasingly worrying both from a quantitative and qualitative side.

The area in Batang district that has the highest number of HIV/AIDS cases is Banyuputih sub-district, with 22 cases, followed by Bandar sub-district with 20 cases and Gringsing subdistrict with 16 cases [2]. This is indicated because in that region there are the most 
prostitution brothels, namely 3 official brothels and some hidden localizations in the form of cafes and karaoke places [2].

This fact shows that FSW is the group most at high risk of contracting and transmitting HIV / AIDS. In Indonesia, it is predicted that more than 50\% of FSW suffer from sexually transmitted diseases. The low knowledge of FSW related to HIV/AIDS and economic reasons are the main causes of the weak efforts to prevent HIV/AIDS transmission carried out by FSW in lokalisasi [3].

Consistent condom use is an effective strategy in the prevention of sexually transmitted infections and transmission of HIV/AIDS [4]. Condoms are currently still a versatile prevention technology that can prevent unwanted pregnancies and sexually transmitted infections including HIV. If used correctly and consistently, condoms can provide the optimal level of protection [5].

In addition to consistent use of condoms, HIV testing for high-risk groups must also be carried out as early as possible and periodically so that early detection of AIDS can be recognized immediately and efforts can be made for prevention and treatment. HIV testing is done to identify, stage, initiate, and monitor infected people with antiretroviral therapy in order to save a sufferer's life [6].

However, in fact, the consistent use of condoms and testing for HIV as early as possible and periodically by FSW as a risk group is still very low. The use of condoms in sexual behavior among FSW in Banyuputih sub-district, Batang district is still low (15.8\%), participation in monthly STI screening is still low (28.1\%), and periodic HIV testing every three months is also low $(26,7 \%)$ [7]. The cause of the low HIV/AIDS prevention behavior must be explored. An assessment of the dangers or threats and vulnerability of AIDS in the FSW group (threat appraisal) and efforts to prevent and handle it (coping appraisal) must be carried out by FSW as a risk group in order to avoid and protect themselves from the threat of HIV/AIDS transmission. Research in 50 countries states that female sex workers (FSW) have a 14-fold higher risk of HIV/AIDS than women of the same age in the general population [8].

The motivations that drive and the factors that prevent a person from engaging in personal protective behavior (Personal Protective Motivation Model) must be identified for interventions to reduce the prevalence of HIV/AIDS transmission today.

Research questions how the consistency of condom-use and HIV tests and their determinants with an assessment of the dangers or threats and vulnerability to AIDS in the FSW. The purpose of this study was to analyze the consistency of condom-use and HIV tests and their determinants using the Personal Protective Motivation (PMT) assessment.

\section{Method}

This type of research is an descriptive-correlative study with a cross sectional design using a quantitative approach. This study was conducted to predict the practice of CondomUse and HIV-Test in female sex workers in the Banyuputih area, Batang district.

The population of this study were all FSW in the Batang district brothel, namely Penundan, Banyuputih and Jentolsari brothels totaling 274 people. The number of samples was calculated according to Slovin minimum sample calculation, which is obtained a number of 163 people. Simple random sample selection technique.

The research instrument in the form of a questionnaire refers to the PMT construction components which consist of: 
1) Extrinsic factors, namely an assessment of peer support or participation in using condoms.

2) Intrinsic factors, namely an assessment of a person's personal perceptions which include: (1) psychological or physical perceptions of not using condoms, (2) perceptions of vulnerability to infection with STIs and HIV, (3) perceptions of the severity of HIV infection, (4) perceptions of effectiveness or the benefits of using condoms, (5) self-efficacy of condom use, and (6) perceptions of barriers or negative consequences of condom use.

3) The intention to use condoms consistently

4) Consistent use of condoms.

The data was collected by filling out a questionnaire which the researcher was waiting for. Data analysis was carried out descriptively to determine the frequency distribution of demographic characteristics, intention to use condoms and consistency of condom use. To analyze the determinants of PMT and condom consistency using the Chi Square test.

\section{Result and Discussion}

Based on the results of the study, of the 163 FSW in Batang, it was found that their average age was 29 years, the youngest FSW was 20 years old and the oldest was 47 years old.

Table 1. Female Sex Worker Characteristic

\begin{tabular}{lcc}
\hline \multicolumn{1}{c}{ Characteristic } & Frequency & $\%$ \\
\hline Education Level & 5 & 3.1 \\
No School & 99 & 60.7 \\
Elementary School & 53 & 32.5 \\
Junior High School & 6 & 3.7 \\
$\quad$ Senior High School & & \\
\hline Merriage Status & 16 & 9.8 \\
$\quad$ Single & 27 & 16.6 \\
$\quad$ Merried & 120 & 73.6 \\
$\quad$ Widowed / divorce & & 29.4 \\
\hline Length of Work as FSW & 48 & 62.6 \\
$\quad<1$ year & 102 & 4.9 \\
1-5 years & 8 & 3.1 \\
6-10 years & 5 & 69.9 \\
$>10$ years & & 30.1 \\
\hline Condom Use & 114 & 62.6 \\
$\quad$ Not always & 49 & \\
Always & & \\
\hline HIV Tes & 102 & \\
Not routine every 3 months & & \\
\end{tabular}




\begin{tabular}{lcc}
\hline \multicolumn{1}{c}{ Characteristic } & Frequency & \% \\
\hline Education Level & & \\
No School & 5 & 3.1 \\
Elementary School & 99 & 60.7 \\
Junior High School & 53 & 32.5 \\
Senior High School & 6 & 3.7 \\
Routine & 61 & 37.4 \\
\hline
\end{tabular}

Table 1 shows that the majority of FSW in Batang Regency are widows/divorced $73.6 \%$. Even so, $16.6 \%$ of FSW were still married and there were $16(9.8 \%)$ FSW who were not married.

Most of the FSW had low education, Elementary School 60.7\%, and Junior High School $32.5 \%$. There were 5 people $(3.1 \%)$ who did not complete elementary school, and there were 6 people $(3.7 \%)$ with high school education.

Most $(66.7 \%)$ of FSW had their work as FSW between 1 and 5 years. There were 13 FSW $(22.8 \%)$ who had been working as FSW for less than 1 year, and $2(3.5 \%)$ had been a FSW for more than 10 years.

\subsection{Factors Affecting Condom Use Practices in Sexual Activity of FSW}

To analyze the factors that influence the practice of condom use in FSW sexual activity, a Chi square test was performed using a cross table.

Table 2. Crosstab between perceived vulnerability, perceived severity, perceived benefits, perceived barriers, knowledge, customer support, pimp support and self-efficacy with the practice of using condoms

\begin{tabular}{|c|c|c|c|}
\hline \multirow{2}{*}{ Variabel } & \multicolumn{2}{|c|}{ Condom Use } & \multirow{2}{*}{$P$ Value } \\
\hline & Not always & Always & \\
\hline \multicolumn{4}{|c|}{$\begin{array}{l}\text { Perceptions of Vulnerability to HIV } \\
\text { transmission }\end{array}$} \\
\hline Not good & $93(76.2 \%)$ & $29(23.8 \%)$ & 0.005 \\
\hline Good & $21(51.2 \%)$ & $20(48,8 \%)$ & \\
\hline \multicolumn{4}{|c|}{ Perceptions of the seriousness of HIV/AIDS } \\
\hline Not good & $88(75.9 \%)$ & $28(24.1 \%)$ & 0.016 \\
\hline Good & $26(55.3 \%)$ & $21(44.7 \%)$ & \\
\hline \multicolumn{4}{|c|}{ Perceptions of the Benefits of Condoms } \\
\hline Not good & $45(90.0 \%)$ & $5(10.0 \%)$ & 0.0004 \\
\hline Good & $69(61.1 \%)$ & $44(38.9 \%)$ & \\
\hline \multicolumn{4}{|c|}{ Perceptions of Barriers to Condom Access } \\
\hline Not good & $33(89.2 \%)$ & $4(10.8 \%)$ & 0.007 \\
\hline Good & $81(64.3 \%)$ & $45(35.7 \%)$ & \\
\hline \multicolumn{4}{|l|}{ Knowledge about HIV/AIDS } \\
\hline Bad & $18(78.3 \%)$ & $5(21.7 \%)$ & 0.448 \\
\hline Good & $96(68.6 \%)$ & $44(31.4 \%)$ & \\
\hline
\end{tabular}

Klien's Support 


\begin{tabular}{llll} 
Less supportive & $97(77.0 \%)$ & $29(23.0 \%)$ & 0.001 \\
Supportive & $17(45.9 \%)$ & $20(54.1 \%)$ & \\
\hline Pimp support & & & \\
Less supportive & $82(73.9 \%)$ & $29(26.1 \%)$ & 0.156 \\
$\quad$ Supportive & $32(61.5 \%)$ & $20(38.5 \%)$ & \\
\hline Self Efficacy & & & \\
Bad & $91(76.5 \%)$ & $28(23.5 \%)$ & 0.005 \\
Good & $23(52.3 \%)$ & $21(47.7 \%)$ & \\
\hline
\end{tabular}

The results of the data analysis showed that the factors that significantly influenced the practice of using condoms consistently in every sexual activity performed by FSW and their clients were: perceived vulnerability to HIV transmission ( $\mathrm{p}$ 0.005), perceptions of HIV/AIDS severity ( $p$ 0.016), perceived benefits. condoms ( $p$ 0.0004), perceived barriers to condom access (p 0.007), customer support (0.001) and self-efficacy (0.005). Meanwhile, knowledge about HIV/AIDS (0.448) and support from pimps (0.156) did not influence the practice of using condoms consistently.

\subsection{Factors Affecting HIV Testing Practices among FSW}

To analyze the factors affecting HIV testing in FSW, a Chi square test was performed using a cross table.

Table 2. Crosstab between perceived vulnerability, perceived severity, perceived benefits, perceived barriers, knowledge, pimp support and self-efficacy with HIV testing practices among FSW

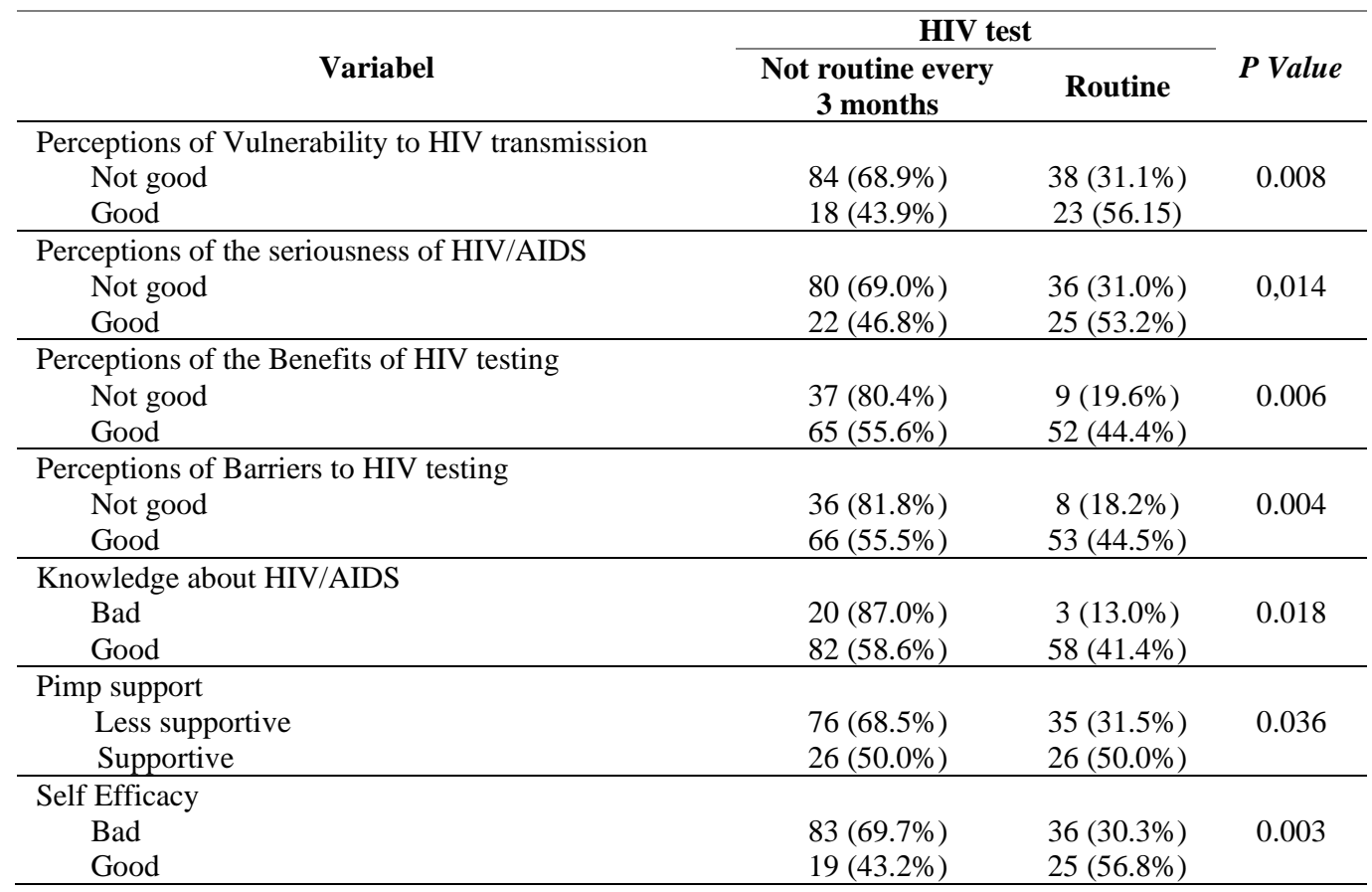


The results of the cross-table analysis above, show that the factors that significantly influence the practice of HIV testing among FSW are: perceived vulnerability to HIV transmission ( $p$ 0.008), perceptions of HIV/AIDS severity (p 0.014), perceived benefits of HIV testing (p 0.006), perception of barriers in HIV testing (p 0.004), knowledge about HIV/AIDS (p 0.018) pimp support (0.036) and self-efficacy (0.003).

FSW is a population at high risk of contracting and transmitting HIV/AIDS due to unsafe sexual behavior. Prevention of transmission is very important for FSW, one of which is the compliance with condom use in risky sexual behavior. The non-compliance of condom use was because the FSW did not dare to refuse sexual intercourse without a condom [9].

The results of this study have proven that Protection Motivation Theory (PMT) which states that the reason for someone to do unhealthy behavior is based on their perception of danger or threat and their susceptibility to disease [10,11,12,13,14]. A person with bad perceptions has a greater tendency to engage in unhealthy behavior. FSW who feel that they are not a group that is vulnerable to HIV/AIDS transmission and think that HIV/AIDS is a common disease and it takes a long time to be infected, so they tend not to take good preventive measures, for example by consistently using condoms every time they have sex with their clients.

PMT theory also explains that when a person is faced with a health threat, there are two judgments that emerge, namely an assessment of the threat and an assessment of coping. Threat assessments provide an individual's assessment of their vulnerability to the threat of HIV infection and the severity of perceived threats. The assessment comes from both personal and intrapersonal perceptions of risky behavior, for example behavior not using condoms. Meanwhile, the coping assessment will compare the effectiveness of the behavior carried out with threats, namely comparing the behavior of using condoms with the threat of HIV infection. The two assessments will ultimately form the motivation (intention) for protective behavior against the threat of HIV infection.

Several previous studies have shown that PMT can predict risky sexual behavior including intention and condom use in the adolescent population [15,16,17,18,19]. In particular, coping assessments have estimated intention to initiate sex among Bahamian youth and intention to use condoms among South African youth [16,18]. Another study in China in 2015 showed that self-efficacy, and the perception of barriers predicted the intention and behavior of using condoms consistently among FSW [20].

There are two factors underlying the behavior of using condoms as HIV/AIDS prevention behavior according to PMT theory, namely:

1) Extrinsic factors, namely an assessment of peer support or participation in using condoms.

2) Intrinsic factors, namely an assessment of a person's personal perceptions which include: (1) psychological or physical perceptions of not using condoms, (2) perceptions of vulnerability to infection with STIs and HIV, (3) perceptions of the severity of HIV infection, (4) perceptions of effectiveness or the benefits of using condoms, (5) self-efficacy of condom use, and (6) perceptions of barriers or negative consequences of condom use 


\section{Conclusion}

The practice of using condoms in sexual activities carried out by FSW with their customers is still low, namely only $30.1 \%$. Most of the FSW did not comply with the HIV test, which should be done regularly every three months.

Factors that significantly influence the practice of using condoms consistently in every sexual activity performed by FSW and their clients are: perceived vulnerability to HIV transmission, perceptions of HIV/AIDS severity, perceptions of condom benefits, perceived barriers to condom access, customer support and self efficacy.

Factors that significantly influence the practice of HIV testing among FSW are: perceived vulnerability to HIV transmission, perceptions of HIV/AIDS severity, perceived benefits of HIV testing, perceived barriers to condom access, knowledge about HIV/AIDS, pimp support and self-efficacy.

Based on the results of the study, the most influencing practice of consistent condom use and routine HIV testing were intrinsic factors (factors in individuals). Therefore, efforts to increase HIV/AIDS transmission prevention behavior in risk groups must be carried out through intensive behavior change communication interventions.

\section{References}

[1] Director General of P2PL, Ministry of Health. Statistics on HIV/AIDS Cases in Indonesia Trimester IV of 2018. Jakarta: Ministry of Health of the Republic of Indonesia. 2018

[1] Batang District AIDS Commission. HIV/AIDS data in Batang District. Batang: Batang District AIDS Commission. 2019

[2] KPA Batang. Kondisi HIV/AIDS di Kabupaten Batang tahun 2019. Batang: KPA Kabupaten Batang. 2019

[3] Exavery, Amon, et.al. Role of condom negotiation on condom use among women of reproductive age in three districts in Tanzania. BMC Public Health. 2012. 12:1097.

[4] Rotrease Regan PhD, MS, MPH, Donald E. Morisky, ScD, ScM, MSPH. Perceptions About HIV and Condoms and Consistent Condom Use Among Male Clients of Commercial Sex Workers in the Philippines. Health Education \& Behavior (HEB). $2013.40(2)$. https://doi.org/10.1177/1090198112446809

[5] Beksinska M, Wong R, Smit J. Male and female condoms: Their key role in pregnancy and STI/HIV prevention. Best Pract Res Clin Obstet Gynaecol. 2019 Dec 14. pii: S15216934(19)30177-4. doi: 10.1016/j.bpobgyn.2019.12.001.

[6] Bharat S. Parekh et al. 2019. Diagnosis of Human Immunodeficiency Virus Infection. Clin Microbiol Rev. 2019 Jan; 32(1). doi: 10.1128/CMR.00064-18.

[7] Fibriana, A.I, Azinar, Muhammad. 2019. Prevention Behavior of HIV/AIDS Transmission in High-Risk Populations. Advances in Social Science, Education and Humanities Research, volume 362. 5th International Conference on Physical Education, Sport, and Health (ACPES).

[8] Baral S et al. 2012. High and disproportionate burden of HIV among female sex workers in lowand middle-income countries: a systematic review and meta-analysis. 19th International AIDS Conference.

[9] Kate Shannon; Joanne Csete. Violence, Condom Negotiation, and HIV/STI Risk Among Sex Workers. JAMA: The Journal of American Medical Asotiation. 2010. 304(5): 573-574.

[10] Aspinwall LG, KemenyME, Taylor SE, Schneider SG, Dudley JP. Psychosocial predictors of gay men's AIDS risk-reduction behavior. Health Psychol. 1991 10:432-44. doi: 10.1037/02786133.10.6.432

[11] Chen X, Stanton B,Gomez P, Lunn S,Deveaux L, BrathwaiteN, et al. Effects on condom use of an HIV prevention programme 36 months postintervention: a cluster randomized controlled trial among bahamian youth. Int J STD AIDS. 2010. 21:622-30. doi: 10.1258/ijsa.2010.010039 
[12] Lwin MO, Stanaland JS, Chan D. Using protection motivation theory to predict condom usage and assess HIV health communication efficacy in singapore. Health Commun. 2010. 25:69-79. doi: $10.1080 / 10410230903473540$

[13] Tanner JF, Hunt JB, Eppright DR. The protection motivation model: a normative model of fear appeals. J. Market. 1991. 55:36-45. doi: 10.2307/1252146

[14] Yan Y, Jacques-Tiura AJ, Chen X, Xie N, Chen J, Yang N, et al. Application of the protection motivation theory in predicting cigarette smoking among adolescents in china. Addict Behav. 2014. 39:181-8. doi: 10.1016/j.addbeh.2013.09.027

[15] Chen X, Stanton B,Gomez P, Lunn S,Deveaux L, BrathwaiteN, et al. Effects on condom use of an HIV prevention programme 36 months postintervention: a cluster randomized controlled trial among bahamian youth. Int J STD AIDS. 2010. 21:622-30. doi: 10.1258/ijsa.2010.010039

[16] Boer H,MashambaMT. Psychosocial correlates of HIV protection motivation among black adolescents in venda, south africa. AIDS Educ Prev. 2005. 17:590-602. doi: 10.1521/aeap.2005.17.6.590

[17] Boer H, Mashamba MT. Gender power imbalance and differential psychosocial correlates of intended condom use among male and female adolescents from venda, south africa. Br. J. Health Psychol. 200712 (Pt.1):51-63. doi: 10.1348/ 135910706X102104

[18] Yu S, Marshall S, Cottrell L, Li X, Liu H, Deveaux L, et al. Longitudinal predictability of sexual perceptions on subsequent behavioral intentions among bahamian preadolescents. Sex Health. 2008. 5:31-9. doi: 10.1071/SH07040

[19] Stanton BF, Fitzgerald AM, Li X, Shipena H, Ricardo IB, Galbraith JS, et al. HIV risk behaviors, intentions, and perceptions among namibian youth as assessed by a theory-based questionnaire. AIDS Educ Prev. 1999. 11:132-149.

[20] Liying Zhang et al, Predictors of Consistent Condom Use Among Chinese Female Sex Workers: An Application of the Protection Motivation Theory Health Care Women Int. 2015 July ; 36(7): 816-833. doi:10.1080/07399332.2014.942902 